\title{
Association between the neutrophil to lymphocyte ratio and prehypertension
}

\author{
Aydin $\mathrm{M}^{1}$, Yuksel $\mathrm{M}^{2}$, Yildiz $\mathrm{A}^{3}$, Polat $\mathrm{N}^{4}$, Bilik $\mathrm{MZ}^{5}$, Akil $\mathrm{MA}^{6}$, Acet $\mathrm{H}^{7}$, Demir $\mathrm{M}^{8}$, \\ Inci $\mathrm{U}^{9}$, Toprak $\mathrm{N}^{10}$
}

Dicle University School of Medicine, Department of Cardiology, Diyarbakir, Turkey. hekimmesut@yahoo.com

\begin{abstract}
OBJECTIVES: To explore the neutrophil-lymphocyte ratio (NLR) in patients with prehypertension (PHT). BACKGROUND: Inflammation plays an important role in the development of cardiovascular diseases. A pathophysiological link also exists between inflammation and PHT. NLR is a simple marker for the assessment of inflammatory status. There is a lack of data regarding the association between NLR and pre-hypertensive state. METHODS: The present cross-sectional study included 33 newly diagnosed PHT patients and 35 normotensive control subjects. Prehypertension was defined as a systolic blood pressure (BP) of 120-139 mm Hg and/or a diastolic BP of $80-89 \mathrm{~mm} \mathrm{Hg}$.

RESULTS: Patients were divided into tertiles based on NLR values: 1.17 (0.9-1.42) in tertile 1; 1.57 (1.43-1.78) in tertile 2; and $2.40(1.82-4.5)$ in tertile 3. The frequency of PHT was significantly higher for patients in the upper NLR tertile compared to the middle and lower NLR tertiles (21 (91.3\%), 7 (30.4\%), and 5 (22.7 \%), respectively; $p<0.001$ ). Systolic BP and diastolic BP were significantly higher among patients in the upper NLR tertile than among those in the other NLR tertiles.

CONCLUSION: An association exists between PHT and NLR. NLR measurement, as well as monocyte count, may be used to indicate increased risk of prehypertension (Tab. 2, Ref. 48). Text in PDF www.elis.sk. KEY WORDS: prehypertension, neutrophil-to-lymphocyte ratio, inflammatory.
\end{abstract}

\section{Introduction}

Prehypertension (PHT) has been defined as a systolic blood pressure (BP) of 120-139 mm Hg and/or a diastolic blood pressure of $80-89 \mathrm{~mm} \mathrm{Hg}(1)$. The PHT designation serves to identify individuals who are potentially at higher risk for developing hypertension (HT) compared to those with optimal BP $(<120 / 80$ $\mathrm{mm} \mathrm{Hg})(2,3)$. In the past few years, several prospective and cross-sectional studies have reported an elevated risk of coronary vascular disease (e.g., coronary heart disease and myocardial infarction) in prehypertensive subjects (4-8). Thus, it is important to understan the pathogenesis of PHT, as PHT may be the first sign of cardiovascular disease (CVD) in some cases.

Several studies have shown that inflammation appears to play an important role in the development of cardiovascular diseases $(9,10)$. Elevated levels of systemic inflammatory markers have been found to be associated with the incidence of cardiovascular diseases, such as coronary artery disease, HT, and atrial fibrillation $(4,5,11)$. White blood cell (WBC) count and its subtypes are related to enhanced cardiovascular risk factors $(6,12)$. The

Dicle University School of Medicine, Department of Cardiology, Diyarbakir, Turkey

Address for correspondence: M. Aydin, Dicle University School of Medicine, Heart Hospital, Department of Cardiology, 21280, Diyarbakir, Turkey. Phone: +90.532 .5633249 , Fax: +90.412 .2488440$ neutrophil-lymphocyte ratio (NLR) has been evaluated as a new predictor for cardiovascular risk (6).

Despite the importance of PHT on cardiovascular outcomes, insufficient data exists on the potential association between the NLR and PHT. The NLR has never been investigated in prehypertensive patients. Therefore, the aim of this study was to explore the NLR in patients with PHT.

\section{Materials and methods}

The present study has a cross-sectional design. Power analysis suggested that a sample size of 25 was needed with an alpha of 0.05 for a power of 0.80 . Thirty-three newly diagnosed PHT patients who had been admitted to our outpatient clinic for general check-up were selected. Thirty-five age- and sex-matched healthy volunteers were recruited for the control group. The investigation complied with the principles outlined in the Declaration of Helsinki. The study was approved by the local ethics committee, and all participants provided written informed consent before participating.

Prehypertension was defined as a systolic BP of 120-139 $\mathrm{mmHg}$ and/or a diastolic BP of $80-89 \mathrm{mmHg}$. BP measurements were performed on the right arm using a sphygmomanometer (Erka, Erlangen, Germany) after 10 minutes of rest in a seated position. The average of two blood pressure measurements obtained at least three minutes apart was recorded for each patient. The nurse specialist determined the mean BP. Ambulatory BP 
Tab. 1. Clinical and hematological characteristics of patients by neutrophil-to-lymphocyte ratio tertiles.

\begin{tabular}{|c|c|c|c|c|}
\hline \multirow[b]{2}{*}{ Variables } & \multicolumn{4}{|c|}{ Neutrophil/lymphocyte ratio } \\
\hline & $\begin{array}{c}\text { Tertile } 1 \\
(1.17 \pm 0.17) \\
n=22\end{array}$ & $\begin{array}{c}\text { Tertile } 2 \\
(1.57 \pm 0.09) \\
\mathrm{n}=23\end{array}$ & $\begin{array}{c}\text { Tertile } 3 \\
(2.40 \pm 0.63) \\
n=23\end{array}$ & $\mathrm{p}$ \\
\hline Age, years & $47 \pm 6$ & $49 \pm 12$ & $45 \pm 13$ & 0.64 \\
\hline Prehypertensive, n (\%) & $5(23)$ & $7(30)$ & $21(91)$ & \\
\hline Body mass index, $\mathrm{kg} / \mathrm{m}^{2}$ & $26.8 \pm 3.6$ & $28.2 \pm 3.5$ & $27.8 \pm 3.9$ & 0.55 \\
\hline Female sex, n (\%) & $14(63)$ & $13(56)$ & $13(56)$ & 0.85 \\
\hline Smoking, n (\%) & $3(13)$ & $7(30)$ & $2(9)$ & 0.12 \\
\hline Mean SBP, mm Hg & $112 \pm 11$ & $114 \pm 12$ & $127 \pm 6$ & $<0.001$ \\
\hline Mean DBP, mm Hg & $72 \pm 9$ & $75 \pm 8$ & $83 \pm 5$ & 0.001 \\
\hline Hemoglobin, g/L & $14.0 \pm 1.2$ & $13.9 \pm 1.3$ & $14.0 \pm 1.7$ & 0.98 \\
\hline Fasting glucose, $\mathrm{mg} / \mathrm{dL}$ & $99 \pm 13$ & $99 \pm 11$ & $100 \pm 12$ & 0.98 \\
\hline $\mathrm{LDL}, \mathrm{mg} / \mathrm{dL}$ & $122 \pm 27$ & $111 \pm 32$ & $110 \pm 19$ & 0.41 \\
\hline Triglyceride, mg/dL & $123 \pm 30$ & $112 \pm 28$ & $104 \pm 42$ & 0.26 \\
\hline $\mathrm{HDL}, \mathrm{mg} / \mathrm{dL}$ & $48 \pm 23$ & $50 \pm 15$ & $41 \pm 11$ & 0.34 \\
\hline Red-cell distribution width, $\%$ & $15.3 \pm 0.9$ & $15.2 \pm 1.0$ & $15.3 \pm 1.2$ & 0.94 \\
\hline Platelet count, $/ \mathrm{mm}^{3}$ & $262 \pm 66$ & $252 \pm 59$ & $262 \pm 57$ & 0.82 \\
\hline Mean platelet volume, fL & $8.29 \pm 1.40$ & $8.11 \pm 1.03$ & $8.28 \pm 1.29$ & 0.93 \\
\hline White blood cell count, $\times 10^{3} / \mu \mathrm{L}$ & $6.9 \pm 1.1$ & $7.5 \pm 1.7$ & $7.8 \pm 1.7$ & 0.15 \\
\hline Neutrophil count, $\times 10^{3} / \mu \mathrm{L}$ & $3.3 \pm 0.5$ & $4.1 \pm 0.9$ & $4.9 \pm 1.1$ & $<0.001$ \\
\hline Lymphocyte count, $\times 10^{3} / \mu \mathrm{L}$ & $2.8 \pm 0.5$ & $2.6 \pm 0.6$ & $2.1 \pm 0.4$ & $<0.001$ \\
\hline
\end{tabular}

DBP - diastolic blood pressure, HDL - high-density lipoprotein, LDL - low-density lipoprotein, SDB - systolic blood pressure

monitoring was not performed. Patients who had PHT but were otherwise healthy were included. Exclusion criteria included drug use, morbid obesity (body mass index $\geq 35 \mathrm{~kg} / \mathrm{m} 2$ ), diabetes mellitus, metabolic syndrome, dyslipidemia, renal dysfunction (serum creatinine $>1.5 \mathrm{mg} / \mathrm{dl}$, blood urea nitrogen $>30 \mathrm{mg} / \mathrm{dl}$ ), heart failure, valvular diseases, asthma, chronic obstructive pulmonary disease, peripheral and cerebral vascular disease, hematological disorders, acute or chronic infection, cancer, inflammatory disease, and hepatic dysfunction.

\section{Biochemical measurements}

Venous blood samples were drawn at initial presentation from the antecubital vein. Total and differential leukocyte counts and routine biochemical tests were performed.

\section{Statistical analysis}

Data were analyzed using the SPSS software version 15.0 for Windows (SPSS Inc., Chicago, Illinois). The KolmogorovSmirnov test was used to verify the normality of the distribution for continuous variables. Continuous variables were defined as mean and standard deviation; categorical variables were given as percentages. The independent sample t test or the Mann-Whitney U test was used for continuous variables, and the chi-square test was used for categorical variables. One-way ANOVA or the KruskalWallis test was performed for the comparison of multiple groups. Pearson analysis was used to evaluate correlations. Statistical significance was defined as $\mathrm{p}<0.05$.

\section{Results}

Patients were divided into tertiles based on NLR values: 1.17 $(0.90-1.42)$ in tertile $1 ; 1.57(1.43-1.78)$ in tertile 2 ; and 2.40
Tab. 2. Baseline clinical and hematological characteristics of prehypertensive and normotensive patients.

\begin{tabular}{|c|c|c|c|}
\hline Variables & Prehypertensive & Control & $\mathrm{p}$ \\
\hline Age, years & $48 \pm 13$ & $46 \pm 9$ & 0.9 \\
\hline Body mass index, $\mathrm{kg} / \mathrm{m}^{2}$ & $27.5 \pm 4.2$ & $27.7 \pm 3.2$ & 0.85 \\
\hline Female sex, n (\%) & $19(58)$ & $21(60)$ & 0.83 \\
\hline Smoking, n (\%) & $5(15)$ & $7(20)$ & 0.6 \\
\hline Mean SBP, mm Hg & $129 \pm 4$ & $107 \pm 5$ & $<0.001$ \\
\hline Mean DBP, mm Hg & $85 \pm 3$ & $70 \pm 4$ & $<0.001$ \\
\hline Hemoglobin, $g / L$ & $13.8 \pm 1.7$ & $14.1 \pm 1.0$ & 0.44 \\
\hline Fasting glucose, $\mathrm{mg} / \mathrm{dL}$ & $101 \pm 12$ & $97 \pm 12$ & 0.17 \\
\hline $\mathrm{LDL}, \mathrm{mg} / \mathrm{dL}$ & $110 \pm 18$ & $118 \pm 33$ & 0.09 \\
\hline Triglyceride, $\mathrm{mg} / \mathrm{dL}$ & $111 \pm 37$ & $115 \pm 32$ & 0.61 \\
\hline $\mathrm{HDL}, \mathrm{mg} / \mathrm{dL}$ & $46 \pm 21$ & $47 \pm 10$ & 0.19 \\
\hline Creatinine, $\mathrm{mg} / \mathrm{dL}$ & $0.85 \pm 0.20$ & $0.77 \pm 0.19$ & 0.13 \\
\hline Red-cell distribution width, $\%$ & $15.4 \pm 1.2$ & $15.1 \pm 0.9$ & 0.25 \\
\hline Platelet count, $/ \mathrm{mm}^{3}$ & $258 \pm 61$ & $259 \pm 60$ & 0.93 \\
\hline Mean platelet volume, fL & $8.4 \pm 1.1$ & $8.0 \pm 1.2$ & 0.13 \\
\hline White blood cell count, $\times 10^{3} / \mu \mathrm{L}$ & $7.4 \pm 1.6$ & $7.4 \pm 1.5$ & 0.88 \\
\hline Neutrophil count, $\times 10^{3} / \mu \mathrm{L}$ & $4.4 \pm 1.2$ & $3.8 \pm 0.9$ & 0.03 \\
\hline Lymphocyte count, $\times 10^{3} / \mu \mathrm{L}$ & $2.2 \pm 0.5$ & $2.7 \pm 0.6$ & 0.002 \\
\hline Neutrophil/lymphocyte ratio & $2.07 \pm 0.74$ & $1.41 \pm 0.29$ & $<0.001$ \\
\hline
\end{tabular}

(1.82-4.50) in tertile 3. Baseline demographic, hemodynamic, and biochemical and hematological characteristics of the study population tertiles are shown in Table 1 . There were no statistically significant differences between the groups with respect to age, gender, body mass index, smoking, or hemoglobin.

The frequency of the prehypertensive state was significantly higher among patients in the upper NLR tertile compared to the middle and lower tertiles (21 (91.3\%), 7 (30.4\%), and 5 (22.7 $\%)$, respectively; $\mathrm{p}<0.001)$. There was no significant difference between the middle and lower NLR tertile groups in terms of pre- 
hypertensive state $(\mathrm{p}=0.559)$. Systolic BP and diastolic BP were significantly higher among patients in the upper NLR tertile (systolic: $127 \pm 6 \mathrm{~mm} \mathrm{Hg}, \mathrm{p}<0.001$; diastolic: $83 \pm 5 \mathrm{~mm} \mathrm{Hg}$ ) than among those in the middle (systolic: $114 \pm 12 \mathrm{~mm} \mathrm{Hg}, \mathrm{p}<0.001$; diastolic: $75 \pm 8 \mathrm{~mm} \mathrm{Hg}, \mathrm{p}<0.001$ ) and lower (systolic: $112 \pm 11$ $\mathrm{mm} \mathrm{Hg}, \mathrm{p}<0.001$; diastolic: $72 \pm 9 \mathrm{~mm} \mathrm{Hg}, \mathrm{p}=0.002$ ) NLR tertiles. Table 2 demonstrates the characteristics of the prehypertensive patients compared to the normotensive controls. Biochemical and hematological parameters were comparable between groups except neutrophil and lymphocyte counts. In the PHT group, neutrophil count was significantly higher $(4.4 \pm 1.2$ versus $3.8 \pm 0.9$; $\mathrm{p}=0.03)$ and lymphocyte count was significantly lower $(2.2 \pm$ 0.5 versus $2.7 \pm 0.6 ; \mathrm{p}=0.002$ ) than in normotensive subjects. As a result, patients with PHT had significantly higher NLR values compared to the control group $(2.07 \pm 0.74$ versus $1.41 \pm 0.29 ; \mathrm{p}$ $<0.001)$. Pearson analysis revealed a positive correlation between NLR and both systolic BP $(r=0.424 ; \mathrm{p}<0.001)$ and diastolic BP $(\mathrm{r}=0.492 ; \mathrm{p}<0.001)$.

\section{Discussion}

In the present study, a higher NLR, a reliable marker of inflammation, was found to be statistically associated with the presence of PHT. In addition, the NLR was significantly correlated with both systolic and diastolic BP.

Many prospective cohort studies have demonstrated an association between BP levels and risk of CVD, stroke, and premature death $(1,13)$. Increased CVD risk begins at systolic BP levels as low as $115 \mathrm{~mm} \mathrm{Hg}$ (14). The longitudinal data from the Framingham Heart Study have clearly shown that individuals with BPs of 120-139/80-89 mm Hg are at increased risk of developing full-blown HT and CVD later in life than individuals with BPs less than 120/80 mm Hg (2). Studies in the United States and other populations have identified an association between increased WBC count and BP (15-17). The relationship between leukocytes and increased cardiovascular risk is well known. Inflammation is involved in the pathogenesis of several CVD (18, 19). Elevated WBC count is associated with deaths from cardiovascular causes, with the extent of coronary heart disease as well as with cardiovascular mortality, combined cardiovascular mortality and morbidity, myocardial infarction, congestive heart failure and stroke (20-25).

Horne et al. examined the predictive ability of total WBC count and its subtypes for risk of death and myocardial infarction. They found that high neutrophil and monocyte counts, low lymphocyte count, and high NLR are independently related to increased number of cardiovascular events (27). Leukocyte subtype counts and NLR are also indicators of systemic inflammation (27). Recent studies have demonstrated the predictive and prognostic significance of the NLR in a wide range of cardiovascular diseases (18, 19, 28-30). Atmaca et al. found that WBC counts were higher in patients with syndrome $\mathrm{X}$ than in control subjects (31). Demirkol et al. have found a significant positive correlation between carotid intima-media thickness values and plasma NLR values (32). These markers have prognostic importance in $\operatorname{CVD}(18,19,26)$.
Several recent studies have supported the hypothesis that inflammatory cells contribute to HT. The TNF- $\alpha$ antagonist etanercept reduces the HT caused by fructose feeding, prevents vascular dysfunction, and blunts the HT caused by angiotensin II. Etanercept was also determined to lower BP in an autoimmune model of chronic inflammation (33-35). In some cases, TNF- $\alpha$ antagonism prevents end-organ damage without lowering BP. For example, etanercept prevents renal injury in salt-dependent HT without lowering BP and reduces albuminuria and renal inflammation in transgenic hypertensive rats $(36,37)$. More recently, the novel, proinflammatory cytokine IL-17 was found to contribute to HT. IL-17 has been implicated in a variety of diseases, including rheumatoid arthritis, inflammatory bowel disease, psoriasis, and airway inflammation (38). IL-17 is also produced by CD8 cells, neutrophils, and natural killer T cells (39-41). IL-17 promotes chemotaxis of other inflammatory cells, in part by stimulating the release of chemokines (42). The vascular accumulation of leukocytes (including $\mathrm{T}$ cells) caused by angiotensin II was determined to be markedly reduced in mice (42). Thus, IL-17 may contribute to the vascular pathophysiology of HT not only via its direct effects, but also by recruiting other inflammatory cells to the perivascular tissue.

Stimuli, such as angiotensin II, sodium, and others, cause a modest elevation in BP to values of approximately 135 to 140 $\mathrm{mm} \mathrm{Hg} \mathrm{(43).} \mathrm{These} \mathrm{initial} \mathrm{elevations} \mathrm{in} \mathrm{pressure} \mathrm{are} \mathrm{largely} \mathrm{due}$ to central actions, but also require the direct effects of angiotensin II on peripheral sites. This first phase of modest pressure elevation, often referred to as prehypertension, causes an inflammatory response, likely by generating neoantigens that activate $\mathrm{T}$ cells. The inflammatory response leads to entry of effector-like T cells into the perivascular fat and the kidneys. Macrophage infiltration is also promoted, in part because of signals from T cells (43).

In the NHANES III and REGARDS studies, individuals with PHT were found to have a higher level of C-reactive protein (44, 45). In the ATTICA study, a range of inflammatory markers, such as tumor necrosis factor- $\alpha$, amyloid A, endothelin 1, homocysteine, advanced glycation products, and elevated WBC counts, were found to be significantly higher in prehypertensives compared to normotensives (46). Recently, Tian et al. investigated the association between specific circulating leukocyte types and BP and found that BP is related to both neutrophils and lymphocytes (47). Kawada et al. showed an independent relationship between neutrophil count and HT (48). Our findings were compatible with these study results.

To our knowledge, this is the first study to show an association between PHT and NLR. Further studies are needed to clarify the role of NLR in PHT patients, especially in relation to biochemical and clinical parameters, before we conclude that NLR may be used as a follow-up marker. This study was limited by a relatively small sample size.

\section{Conclusion}

An association exists between PHT and NLR. NLR measurement, as well as monocyte count, may be used to indicate increased risk of prehypertension. 


\section{References}

1. Chobanian AV, Bakris GL, Black HR et al. The Seventh Report of the Joint National Committee on Prevention, Detection, Evaluation, and Treatment of High Blood Pressure: the JNC 7 report. JAMA. 2003; 289 (19): $2560-2572$.

2. Vasan RS, Larson MG, Leip EP, Kannel WB, Levy D. Assessment of frequency of progression to hypertension in nonhypertensive participants in the Framingham Heart Study; a cohort study. Lancet 2001; 358 (9294): 1682-1686.

3. Vasan RS, Beiser A, Seshadri S et al. Residual lifetime risk for developing hypertension in middle-aged women and men: The Framingham Heart Study. JAMA 2002; 287 (8): 1003-1010.

4. Folsom AR, Wu KK, Rosamond WD, Sharrett AR, Chambless LE. Prospective study of hemostatic factors and incidence of coronary heart disease: the Atherosclerosis Risk in Communities (ARIC) Study. Circulation 1997; 96 (4): 1102-1108.

5. Kocaman SA, Sahinarslan A, Kunak T et al. The particular interactions of the traditional cardiovascular risk factors with different circulating specific leukocyte subtype counts in blood: an observational study. Anadolu Kardiyol Derg 2011; 11 (7): 573-581.

6. Tamhane UU, Aneja S, Montgomery D, Eagle KA, Gurm HS. Association between admission neutrophil to lymphocyte ratio and outcomes in patients with acute coronary syndrome. Am J Cardiol 2008; 102 (6): 653-657.

7. Vasan RS, Larson MG, Leip EP, Evans JC, O’Donnell CJ, Kannel WB et al. Impact of high-normal blood pressure on the risk of cardiovascular disease. N Engl J Med 2001; 345 (18): 1291-1297.

8. Qureshi AI, Suri MF, Kirmani JF, Divani AA, Mohammad Y. Is prehypertension a risk factor for cardiovascular diseases. Stroke 2005; 36 (9): 1859-1863.

9. Ross R. Atherosclerosis - an inflammatory disease. N Engl J Med. 1999; 340 (2): 115-126.

10. Libby P. What have we learned about the biology of atherosclerosis? The role of inflammation. Am J Cardiol 2001; 88 (7B): 3J-6J.

11. Imtiaz F, Shafique K, Mirza SS, Ayoob Z, Vart P Rao S. Neutrophil lymphocyte ratio as a measure of systemic inflammation in prevalent chronic diseases in Asian population. Int Arch Med 2012; 5 (1): 2.

12. Uthamalingam $S$, Patvardhan EA, Subramanian $S$ et al. Utility of the neutrophil to lymphocyte ratio in predicting long-term outcomes in acute decompensated heart failure. Am J Cardiol 2011; 107 (3): 433-438.

13. Lewington S, Clarke R, Qizilbash N, Peto R, Collins R. Prospective Studies Collaboration. Age-spesific relevance of usual blood pressure to vascular mortality: a meta-analysis of individual data for one million adults in 61 prospective studies. Lancet 2002; 360 (9349): 1903-1913.

14. Lawes CM, Vander Hoorn S, Rodgers A. International Society of Hypertension. Global burden of bloodpressure-related disease. Lancet 2008; 371 (9623): 1513-1518.

15. Ford ES. The metabolic syndrome and C-reactive protein, fibrinogen, and leukocyte count: findings from the Third National Health and Nutrition Examination Survey. Atherosclerosis 2003; 168 (2): 351-358.

16. Oda E, Kawai R. Comparison between high-sensitivity C-reactive protein (hs-CRP) and white blood cell count (WBC) as an inflammatory component of metabolic syndrome in Japanese. Intern Med 2010; 49 (2): $117-124$.
17. Oda E, Kawai R. The prevalence of metabolic syndrome and diabetes increases through the quartiles of white blood cell count in Japanese men and women. Intern Med 2009; 48 (13): 1127-1134.

18. Hartaigh B, Bosch JA, Thomas GN et al. Which leukocyte subsets predict cardiovascular mortality? From the Ludwigshafen Risk and cardiovascular health (LURIC) study. Atherosclerosis 2012; 224 (1): 161-169.

19. Sen N, Afsar B, Ozcan F, Buyukkaya E, Isleyen A, Akcay AB et al. The neutrophil to lymphocyte ratio was associated with impaired myocardial perfusion and long term adverse outcome in patients with ST-elevated myocardial infarction undergoing primary coronary intervention. Atherosclerosis 2013; 228 (1): 203-210.

20. Margolis KL, Manson JE, Greenland $P$ et al. Leukocyte count as a predictor of cardiovascular events and mortality in postmenopausal women: the Women's Health Initiative Observational Study Arch. Intern Med 2005; 165 (5): 500-508.

21. Kostis JB, Turkevich D, Sharp J. Association between leukocyte count and the presence and extent of coronary atherosclerosis as determined by coronary arteriography. Am J Cardiol 1984; 53 (8): 997-999.

22. Lee CD, Folsom AR, Nieto FJ, Chambless LE, Shahar E, Wolfe DA. White blood cell count and incidence of coronary heart disease and ischemic stroke and mortality from cardiovascular disease in AfricanAmerican and White men and women: atherosclerosis risk in communities study. Am J Epidemiol 2001; 154 (8): 758-764.

23. Schillaci G, Pirro M, Pucci G et al. Prognostic value of elevated white blood cell count in hypertension. Am J Hypertens 2007; 20 (4): 364-369.

24. Friedman GD, Klatsky AL, Siegelaub AB. The leukocyte count as a predictor of myocardial infarction. N Engl J Med 1974; 290 (23): $1275-1278$.

25. Bekwelem W, Lutsey PL, Loehr LR et al. White blood cell count, C-reactive protein, and incident heart failure in the Atherosclerosis Risk in Communities (ARIC) Study. Ann Epidemiol 2011; 21 (10): 739-748.

26. Horne BD, Anderson JL, John JM et al. Intermountain heart collaborative study group. Which white blood cell subtypes predict increased cardiovascular risk? J Am Coll Cardiol 2005; 45 (10): 1638-1643.

27. Momiyama Y, Kawaguchi A, Kajiwara I et al. Prognostic value of plasma high-sensitivity C-reactive protein levels in Japanese patients with stable coronary artery disease: the Japan NCVC-Collaborative Inflammation Cohort (JNIC) Study. Atherosclerosis 2009; 207 (1): 272-276.

28. Kaya H, Ertas F, Islamoglu $Y$ et al. Association between neutrophil to lymphocyte ratio and severity of coronary artery disease. Clin Appl Thromb Hemost 2014; 20 (1): 50-54.

29. Yildiz A, Kaya H, Ertas F et al. Association between neutrophil to lymphocyte ratio and pulmonary arterial hypertension. Turk Kardiyol Dern Ars 2013; 41 (7): 604-609.

30. http://cat.sagepub.com/

31. Atmaca Y, Ozdol C, Turhan S, Vurgun K, Duzen V, Erol C. The association of elevated white blood cell count and C-reactive protein with endothelial dysfunction in cardiac syndrome X. Acta Cardiol 2008; 63 (6): 723-728.

32. Demirkol S, Balta S, Unlu M et al. Neutrophils/Lymphocytes Ratio in Patients With Cardiac Syndrome X and Its Association With Carotid Intima-Media Thickness. Clin Appl Thromb Hemost 2012; 20 (3): 250-255.

33. Tran LT, MacLeod KM, McNeill JH. Chronic etanercept treatment prevents the development of hypertension in fructose-fed rats. Mol Cell Biochem 2009; 330 (1-2): 219-228. 
34. Guzik TJ, Hoch NE, Brown KA et al. Role of the T cell in the genesis of angiotensin II induced hypertension and vascular dysfunction. J Exp Med 2007; 204 (10): 2449-2460.

35. Venegas-Pont M, Manigrasso MB, Grifoni SC et al. Tumor necrosis factor-alpha antagonist etanercept decreases blood pressure and protects the kidney in a mouse model of systemic lupus erythematosus. Hypertension 2010; 56 (4): 643-649.

36. Elmarakby AA, Quigley JE, Imig JD, Pollock JS, Pollock DM. TNF-alpha inhibition reduces renal injury in DOCA-salt hypertensive rats. Am J Physiol Regul Integr Comp Physiol 2008; 294 (1): R76-83.

37. Muller DN, Shagdarsuren E, Park JK et al. Immunosuppressive treatment protects against angiotensin II-induced renal damage. Am J Pathol 2002; 161 (5): 1679-1693.

38. Witowski J, Ksiazek K, Jorres A. Interleukin-17: a mediator of inflammatory responses. Cell Mol Life Sci 2004; 61 (5): 567-579.

39. Kondo T, Takata H, Matsuki F, Takiguchi M. Cutting edge: Phenotypic characterization and differentiation of human $\mathrm{CD} 8 \mathrm{~T}$ cells producing IL-17. J Immunol 2009; 182 (4): 1794-1798.

40. Li L, Huang L, Vergis AL et al. IL-17 produced by neutrophils regulates IFNgamma-mediated neutrophil migration in mouse kidney ischemiareperfusion injury. J Clin Invest 2010; 120 (1): 331-342.

41. Lee KA, Kang MH, Lee YS et al. A distinct subset of natural killer $\mathrm{T}$ cells produces IL-17, contributing to airway infiltration of neutrophils but not to airway hyperreactivity. Cell Immunol 2008; 251 (1): 50-55.
42. Hartupee J, Liu C, Novotny M, Li X, Hamilton T. IL-17 enhances chemokine gene expression through mRNA stabilization. J Immunol 2007; 179 (6): 4135-4141.

43. Harrison DG1, Guzik TJ, Lob HE et al. Inflammation, Immunity, and Hypertension. Hypertension 2011; 57 (2): 132-140.

44. Wang Y, Wang QJ. The prevalence of prehypertension and hypertension among US adults according to the new joint national committee guidelines: new challenges of the old problem. Arch Intern Med 2004; 164 (19): 2126-2134.

45. Glasser SP, Judd S, Basile J et al. Prehypertension, Racial Prevalence and Its Association With Risk Factors: Analysis of the REasons for Geographic And Racial Differences in Stroke (REGARDS) Study. Am J Hypertens 2011; 24 (2): 194-199.

46. Chrysohoou C, Pitsavos C, Panagiotakos DB, Skoumas J, Stefanadis C. Association between prehypertension status and inflammatory markers related to atherosclerotic disease: the ATTICA Study. Am J Hypertens 2004; 17 (7): 568-573.

47. Tian N, Penman AD, Mawson AR, Manning RD Jr, Flessner MF. Association between circulating specific leukocyte types and blood pressure: the atherosclerosis risk in communities (ARIC) study. J Am Soc Hypertens 2010; 4 (6): 272-283.

48. Kawada T, Morihashi M, Ueda H, Sirato T. Neutrophil cell count is related to hypertension in workers: a cross-sectional study. Vasc Dis Prev 2007; 4 (3): 225-228. 